\title{
Review
}

\section{Occupational Medicine in the Slovene Area}

\author{
Marjan BILBAN \\ Occupational Traffic and Sports Medicine, Institute of Occupational Safety, Slovenia
}

\begin{abstract}
Occupational Medicine in the Slovene Area: Marjan BILBAN. Occupational Traffic and Sports Medicine, Institute of Occupational Safety, Slovenia-Slovenia is a small, fast developing country in the EU with approximately 2,000,000 inhabitants and 700,000 employed. Occupational medicine has been present in Slovenia for as long as 500 yr. Today, 130 specialists of occupational medicine are in charge of health protection of the employed (including transport workers and athletes). There are also 1,100 safety engineers, who take care of the technical side of occupational safety. We are guided in our work by modern occupational health and safety legislation, which is based on EU directive 89/391EEC. The average sick leave rate in Slovenia is about $4.7 \%$, caused mostly by injuries, bone, muscle and connective tissue diseases and respiratory diseases. Sick leave appears most frequently in the textile industries and coal mining. Annually, around 26,000 occupational injuries (32.7 per 1,000 employed) and 25 fatalities ( 3 per 100,000 employed) occur. Most injuries occur in construction, manufacturing and farming. Each year there are 8,500 disablility cases $(2,500$ disability retirements-most caused by mental illnesses), but only 30 acknowledged cases of occupational diseases (mostly occupational skin diseases, asthma and asbestosis). Occupational medicine in Slovenia is strongly associated with occupational medicine in the more developed European countries. It is therefore moving out of clinics and into the working environment, where its goals lie in primary prevention, i.e. establishing and keeping healthy working environments that guarantee high productivity, health and well-being of workers as a whole.
\end{abstract}

(J Occup Health 2005; 47: 193-200)

Key words: Occupational health practice, Occupational medicine, Occupational health legislation, Health conditions, Prevention, Slovenia

Received Oct 1, 2004; Accepted Feb 28, 2005

Correspondence to: M. Bilban, Occupational Traffic and Sports Medicine, Institute of Occupational Safety, Chengdujska 25, SI 1000 Ljubljana,Slovenia (e-mail:marjan.bilban@zvd.si)

\section{History of Occupational Medicine}

The origins of occupational medicine in Slovenia go as far back as the 16th (Paracelsus 1493-1541, Matioli 1500-1577), 18th (Scopoli 1723-1788) and the 19th centuries (Gerbec 1808-1880). At the beginning of the 18 th century Idria employed a healer to treat mercury miners. He was paid by the government, which also paid small amounts to sick miners and had taken responsibility for a mutual fund. In 1740 the Austrian (Habsburg) government employed a surgeon, whose work was to prevent and cure occupational intoxication due to mercury and to help in the case of mining accidents. In 1754 Joannes Antonius Scopoli took over the work as a physician and stayed for fifteen years. In 1761 Scopoli published a discussion about mercury in Idria, part of which dealt with miners' illnesses. The physicians who worked in Idria wrote about the effects of mercury on the miners. They possessed more knowledge about mercury toxicology than anyone else in Europe.

In 1858, the first mutual fund in Leša at Prevalje was created. Injury and illness insurance became compulsory in Austria (Slovenia was part of the Austrian monarchy at the time) in 1887 and 1888 . Mines were the first to employ medical doctors, and then iron-works founded the first hospitals, which were actually the predecessors of workshop outpatient departments of today.

In 1863 another mutual fund was founded in Mežica valley, the second Slovene mining district. This marked the beginning of organized medical care for miners and lead smelters. In 1903 a physician in Crna hospital (with the capacity of 35 beds) performed preliminary medical examinations for the first time.

Soon after World War II outpatient departments were founded in a number of factories and workshops. In 1960 the Institute for Technical and Medical Safety of Slovenia, which later changed its name to the Institute of Occupational Safety (IOS), was founded. Today, IOS performs comprehensive occupational technical activities relating to work and living environments as well as medical care, education and publication.

To achieve a better development of active occupational 
health care and preventive activities, the first occupational medicine dispensaries were founded in 1965. These dispensaries linked the work of workshop departments and contributed to raising the level of expert knowledge. In 1971 the head organization of active occupational health care for workers in Slovenia-The Institute for Occupational, Traffic and Sport Medicine-was founded.

Since 1991, social, political and economic transitions have introduced remarkable changes in the activities of occupational medicine. Outpatient departments of workshops have declined (from 161 in year 1991 to only two in year 2001) and employers and companies have substantially decreased the amount of money allocated to occupational health care of workers ${ }^{1)}$.

\section{Occupational Medicine Today}

Recognized units of occupational, traffic and sports medicine perform the functions of active occupational health care at the primary, secondary and tertiary levels. The primary and secondary levels are performed in the form of public health care services by public health care institutions or licensed private medical practitioners.

The following units of occupational, traffic and sports medicine perform the preventive occupational health care of workers, drivers and athletes:

* Occupational medical clinics (carrying out the preventive and curative health care at the primary level)

* Dispensaries of occupational, traffic and sport medicine (carrying out mainly preventive health care), founded in all regions (60)

* The Institute for Occupational, Traffic and Sports Medicine (IOTSM) (carries out preventive and complex health care)

Units of public institutions, companies and others (private medical practitioners) are authorized to perform preventive health care of workers; medical doctors in these units are licensed.

Employers can make a contract with an authorized contractor employing a licensed medical doctor or with a private licensed practitioner. The amount and nature of the work done in the medical clinic are left to the interest, financial capabilities and knowledge of both partners - the company and the clinic, while both must work in accordance with established expertise. When it comes to more demanding procedures, clinics cooperate with a regional dispensary or the IOTSM.

The goals of medical clinics are to encourage increased worker productivity and to achieve better economic conditions without putting workers' life or health at risk. Having technical-safety units of the company in the vicinity helps settling workers' health care questions. At the same time, a market-oriented company realizes that active health care of the workers is not only a humane question, but also an important economic activity.

The IOTSM performs the activity of occupational health care at primary, secondary and tertiary levels. The basic occupational health care (prevention and treatment) is performed in dispensaries of occupational medicine. The IOTSM also performs specialist health care (at the secondary level) and some tertiary level activities involving teaching, research and development.

There are 161 licensed specialists in the field of occupational, traffic and sports medicine or specialists of occupational medicine in Slovenia. In addition, 38 students are finishing their studies and there are eight candidates for the license in occupational medicine who have undertaken their specialization abroad. One hundred and thirty-four specialists work in the network of occupational medicine (the rest work for medical insurance institutions, invalidity commissions of the first or second level, Institute of Rehabilitation, etc.).

The Extended Expert Collegium of occupational, traffic and sports medicine is an expert body of the Ministry of Health. Members of the collegium are renowned experts, who help develop the basic principles and also encourage the implementation of expert control. The Collegium actively modernizes the field of occupational medicine and contributes to the harmonization of Slovene legislation with the complex EU legislation on occupational safety.

The physicians who work in the field of occupational medicine belong to the Section of Occupational Medicine within the Slovene Medical Association. The section is led by the Executive Board that meets monthly to debate the important question of development in the field, cooperation with other organizations at home and abroad and to attend to permanent education by means of organizing expert meetings. One hundred and sixty members are experts in the field of occupational medicine and 50 more members come from other branches of medicine and science ${ }^{1-3)}$.

Physicians work $40 \mathrm{~h}$ a week and perform three different kinds of medical activities:

* patient treatment (family medicine)

* prevention (occupational, traffic and sports medicinepreventive physical examinations, analysis of working posts, risk assessment, etc.)

* other activities (working for the Institute of Medical Insurance of Slovenia (IMIS), The Pension and Disability Insurance Institute of Slovenia (IPDI), IOTSM, the Ministry, the Labor Inspectorate, in education or doing administrative work, etc.)

Patient treatment takes on average $29.8 \%$ of the working time of physicians, prevention $64 \%$ and other activities $6.2 \%$. Differences between regions are substantial.

In 1965 the first educational program for occupational safety in Slovenia was launched. Since then 1,100 safety engineers have graduated from college programs and 200 from university programs. Many have graduated from 
universities in former Yugoslavia. Safety engineers belong to a section of more than 800 members and to the Association of Occupational Health and Safety. The Association meets all the conditions to become a core body in creating and implementing the policies and measures for health and safety at work in the country. Members of the Association are safety engineers and other experts, who cooperate in the field of safety in the working environment. More than 300 individuals and 290 companies have already become members.

In Slovenia 300 authorized contractors carry out expert tasks in the field of occupational safety and health at different levels. They perform some or all of the following tasks:

* periodical examinations of chemical, physical and biological harmful effects in the working environment * periodical tests and inspections of work equipment

* elaboration of expert proposals for the safety assessment by the employer

* preparation and implementation of education on the subject of work safety

Another body of the Ministry of Health is the Republic Labor Inspectorate, which employs around 80 highly skilled experts for controling the field of occupational safety and health and legal working relationships. In the years 1998-2003 there were on the average per year 6,500 inspections and controls performed by the inspectorate.

The regulatory provisions related to these tasks commonly refer to:

- (not) performing the preventive health examinations

- (not) training workers in safety

- (not) performing periodical inspections of the working environment

- (not) providing personal safety equipment

- (not) performing periodical inspection and tests of the work equipment

The inspectors deal with about 400 severe occupational injuries every year. Most accidents happen in small companies or among private entrepreneurs. Generally, young men are especially at risk.

\section{The Role of Occupational Medicine in Occupational Safety and Health Legislation}

The role of occupational medicine, in particular that of the specialist physician, is very clearly stated in the new Law of Occupational Safety and Health (Official Gazette RS, no. 56/99). Article 3 explains that the "authorized physician" is a specialist of occupational medicine, who is entrusted to perform expert tasks of occupational safety and health by the employer. It is compulsory for the employer to entrust such expert tasks to an authorized physician. These tasks, in accordance with the provisions of Convention No. 161 on occupational health services and the EU framework directive, 89/391/EEC, are stated in Article 20. The tasks correspond to the tasks of the specialist in the field of occupational, traffic and sports medicine under the definition of active occupational health care and represent the basic principles of occupational medicine.

The Law of Occupational Safety and Health requires a specialist to perform tasks that a specialist physician is unable to perform by himself: i.e. cooperating in risk assessment at the workplace and in the working environment. The physician's collaborators are safety engineers, technology engineers, heads of production, the human resources departments, employers and the workers themselves.

The specialist physician in the field of occupational medicine cannot perform any of these tasks, unless a technical specialist cooperates in the risk assessment of the working environment. The move from the clinic to the workplace has today become a necessity. The need to communicate with experts in other fields, employers and workers is an indispensable part of everyday routines for any specialist physician of occupational, traffic and sport medicine.

When the specialist physician establishes a health disorder in the case of a worker he is entrusted with, he must always determine, whether the disorder is linked to the working conditions and propose appropriate measures to be implemented in order to prevent similar occurrences. The physician can propose a change in diet, working breaks as well as relevant important measures, e.g. ergonomic adjustments to the work place or certain administrative measures to keep workers healthy. Advising on the purchase of new machines, working clothes and personal safety equipment is part of these preventive measures.

One of the tasks that is also a preventive measure is to instruct workers about hazards connected to their work or workplace and health education of the workers. By doing so, the physician plays an important part in the promotion of their health.

The physician determines causes of occupational diseases and work-related disorders. An emphasis should be placed on what should logically follow-the prevention of new diseases. That means that workplace must be improved. Exposure to hazards in question is linked to the probability of contracting a disease. The diagnosis of an occupational disease differs from that of a clinical disease only in terms of exposure and etiology. The question is, whether the materials, conditions or other factors of the working environment fundamentally influence the development of the disease, and whether we can therefore call it an occupational disease. It is quite clear that the diagnosis of an occupational disease is important firstly for protecting the workers' rights and for the redesign of the working environment. It is secondly important for relevant research.

Occupational diseases are caused directly by the 
working processes or working conditions particular to a certain workplace or by work that is part of the occupational activity that is covered by insurance. A disease is not occupational, unless it is on the list of occupational diseases. A worker that has been diagnosed with an occupational disease must be transferred to another workplace. His earlier workplace should be rearranged, so that other workers are not affected. The physician, the safety engineer and other technical staff should all participate in the redesign process.

Previously, preventive examinations were the most frequent medical activity of the specialist physician of occupational, traffic and sports medicine. Today the specialist physician has to perform all sorts of different activities. Therefore examinations should no longer take so much of his working time.

Risk assessments and legislation determine the amount of time in which examinations should be carried out. The results of examinations should include:

* an opinion on working capability (meeting the specific health criteria for a certain working environment) and suggestions for improving the working conditions of individual workers

* a final report with useful suggestions on how to improve conditions, reorganize workplaces and change the work structure, all of which would improve the workers' health. The report should also include the dates of subsequent examinations. It would be necessary for the specialist to report his conclusions to the management of the company, present his suggestions and back them up with scientific facts.

The Law of Occupational Safety and Health requires a specialist physician of occupational, traffic and sport medicine to perform the health care of occupationally diseased workers. The authorized physician is required to ensure that the worker is no longer exposed to the harmful factors, and his efforts should include rearranging the workplace. Drug prescriptions, specialist examinations (of other medical fields) and hospital treatment should all be under the control of the physician chosen by the worker concerned. The authorized physician should take care of the treatment and aid so as help to achieve a quick recovery of the worker to his post. The tasks of a specialist physician of occupational, traffic and sports medicine also include organization of first aid and evacuation in cases of occupational injuries or accidents. This means that he helps the employer to organize first aid in such a way that there is on each shift a person who can administer first aid and knows where the first aid kit is and the appropriate telephone numbers.

An authorized physician should also be aware of the working conditions and the types of injuries that can occur in a particular workplace, and therefore he should also advise on the contents of first aid kits.

The physician should organize first aid courses for all workers or those who are selected for administering first aid. He must also make sure that the telephone numbers of the emergency services and a nearby medical institution are written near every telephone in the factory. The physician establishes causes of disablement and suggests preventive measures. The physician is also in charge of rehabilitation and counseling on a new appropriate workplace for the disabled person. The physician establishes whether there is a connection between the disability and the workplace. This is important for the company as it is neither distinguished nor economically wise to produce disabled workers. The cost for the company of having many workers retired because of disability is not direct, but the indirect consequences can be very significant.

Most such retirements are regarded as level III, which means that the worker is able to return to work, but he is not able to perform all of his former duties. Furthermore, the employer is often unable to provide this worker with an appropriate position. This is another reason for preventive measures to be implemented before a problem occurrs. The authorized physician can speak on behalf of a disabled worker before the expert body of the Institute of Pension and Disability Insurance and inform the members what measures can be taken by the company in order to provide a new post for the worker.

The physician's role in the rehabilitation process is clearly stated in the Law of Pension and Disability Insurance and is very important. The employer is obliged to organize the rehabilitation, which is then covered by the Institute for Pension and Disability Insurance. Through the rehabilitation process the worker's duties are adjusted to his capabilities, he learns how to do his job without damage to his health, adopts new skills on how to operate new adjusted equipment and gains knowledge.

Another task of the physician is to propose measures to improve the health of those workers, who are particularly at risk in their jobs. He can propose special diets, working breaks or recreation after shifts. Workers should spend their free time without exhausting themselves, while trying to preserve their abilities, so that they will be able to work their next shift at full strength and in a good mental condition.

The specialist of occupational, traffic and sports medicine advises the employer how to organize the working processes, e.g. shifting posts in the processes divided into separate working operations. By doing that, we can change the workload, decrease the probability of health disorders and increase workers' interest for the products they help to manufacture.

The Law of Occupational Safety and Health also requires the specialist to keep evidence of his activities, as is stipulated in the special regulations. The new legislation consistently covers both occupational medicine 
and occupational safety which are the keys to occupational health and safety. Both professions cooperate in the risk assessment of workplaces, which elevates the credibility of this area and makes cooperation with employers much easier. The employers undertake all responsibilities according to the new legislation. They also play a key role in occupational health and safety. When employers sign the safety declaration, they obligate themselves to carry out a program of improving working conditions in their companies. They can improve the working processes so as to better suit their workers, and regulate relations between workers and their superiors. Workers need to feel that their work matters to the company and that they contribute to the company's success. Increasing workers' motivation is the most successful way of reducing sick leave.

Positive features of occupational medicine in Slovenia:

* a long tradition of occupational health care, which was based on factory outpatients' departments in formerYugoslavia

* fine education of specialists of occupational medicine

* additional education of nurses

* additional courses for psychologists working in the field of occupational medicine

* the activities of different societies and the Association of Safety Engineers that have a good system of continuous education in the field of safety

* a relatively small number of fatalities

Negative features:

* safety engineers lack knowledge about the fields of industrial hygiene, ergonomics, psychology and occupational medicine

* communication between institutions is not as good as it should be, because experts are not always willing to be parts of a team

* a free market of services and an undefined network of activities mean that less qualified individuals (without a license) and retired people can perform health care activities

* physicians focus too much on treatment and preventive examinations

* there is no system for discovering or verifying occupational disease, and no national database

* expert supervision is often inadequate

* there is not enough cooperation between occupational medicine and Labor Inspectors

* there are no interdisciplinary courses

* the status of the institute responsible for establishing the health of workers is unclear

* there is no uniform national information system for occupational health and safety

According to the legislation and recent developments, the following institutions will play a bigger role in the future: - The Occupational Safety and Health Council, which has already been formed (on the basis of the Law of Safety and Health at work), but has not yet begun to operate; -Administrative bodies responsible for the protection of workers' health (modernization of the inspection bodies);

-An institute for protecting workers' health (the formation of a professional doctrine, expert, research, development and education in the field of workers' health protection);

-New insurance for health and safety at work on the basis the of bonus-malus system (employers with low expenses for occupational injuries and diseases pay lower insurance than those with higher expenses), intended for all employers, will replace the existing forms of insurance;

-A post-graduate educational institution of public health, which will provide multidisciplinary education in the field of public health, with special programs for health and safety at work for post-graduate students of medicine, technology and other professions. All students will focus on occupational health and safety and later on become ergonomists, hygienists or specialists in other professions (economists, jurists, psychologists, sociologists, work organizers, etc.).

\section{Health Conditions of the Employees ${ }^{4)}$}

The health conditions of the Slovene employees were established with the help of the following data: social and medical analysis of sick leave rate (data source: Institute of Public Health of the Republic of Slovenia), occupational injuries and fatalities (data source: Institute of Public Health of the Republic of Slovenia), disability retirements (data source: invalidity commission's work analysis, the Pension and Disability Insurance Institute of Slovenia).

Analysis of sick leave data demonstrates that 17 workdays per worker are annually lost and that 37,000 employees are on sick leave each day $(4.7 \%$ of all employees). The statistics have not changed much in recent years $(5.0 \%$ in $1990,4.6-4.7 \%$ in the last few years).

Women spend more time on sick leave than men. Injuries are the most frequent cause for going on sick leave in Slovenia and are followed by bone disease, muscle disease and respiratory disease (Fig. 1).

Men are absent from work mostly because of injuries (2.5 times more absences than women), women because of muscle and bone disease.

When percent sick leave is calculated by the percentage of sick leave days in the total number of workdays for all employees, the textile industries and coal mining are faced with the highest percentage of sick leave $(7 \%)$. In contrast, retail sales face the lowest percentage (3.5\%).

Work injury statistics indicate that the situation in Slovenia does not substantially differ from the EU average. The number of injuries has remained more or 
less the same during the last decade (Figs. 2 and 3). The EU expansion of 1986 could be responsible for the slight increase in the number of lost workdays in the $\mathrm{EU}$ in that period.

In 2000, 25,940 work injuries were reported, which amounted to 32.7 per 1000 employees $(19,384$ men $44.6 \%$ of all male employees and 6,556 women $18.3 \%$ ). There were 26 fatalities ( 3 per 100,000 employees).

There were 22,375 employees who were injured at work or on business trips (28.2\%o of all employees), and the rest were injured on the way to or from work. The largest number of injuries occurred in construction, manufacturing, agriculture, traffic and public administration.

Employees aged 15-19 and 20-24 were injured the

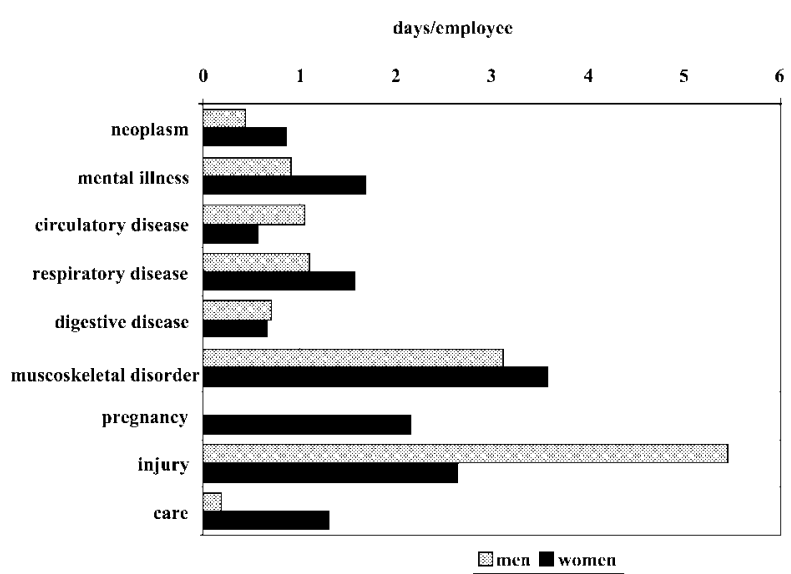

Fig. 1. Number of lost workdays, Slovenia, 20024). most frequently ( $52.5 \%$ and $46.2 \%$ ), in contrast to the age group of over 55 (22.3\%o)

Injuries to the following parts of the body were the most common: the hand, wrist and fingers $(35 \%)$, the ankle, foot and toes $(18.1 \%)$, the torso $(14.2 \%)$, the legs $(10.9 \%)$ and the arms $(8 \%)$.

Workdays lost due to these injuries: finger injuries $23.7 \%$, torso injuries $16.5 \%$, leg injuries $12 \%$ and arm injuries $10.2 \%$ of all lost workdays.

Injuries were most frequently caused by a fall or a slip on same level $(21.4 \%)$, by a falling object $(13.6 \%)$ or by hitting an object (11.1\%).

Manufacturing and construction claimed the most casualties (together almost 70\%).

The data on fatal occupational accidents demonstrate that the situation in Slovenia has improved significantly in the last decade and is very close to the EU average. However, unlike other statistics, our data includes injuries acquired on the way to and from work (traffic accidents), which represent $25 \%$ of all fatal accidents.

The total number of disability retirements in Slovenia has not changed much in the last thirteen years. The number of category I retirements has decreased, while the number of category III retirements (workers able to perform their previous duties or other less demanding work) has increased. Category I retirements are most frequently caused by mental illnesses, neoplasms and circulatory diseases, category II (workers are able to work only half-time) by bone, muscle and connective tissue diseases, mental illnesses and neoplasms, whereas category III is most frequently caused by bone, muscle and connective tissue diseases, followed by injuries and mental illnesses (Fig. 4).

Invalidity commissions' expert opinions are the only

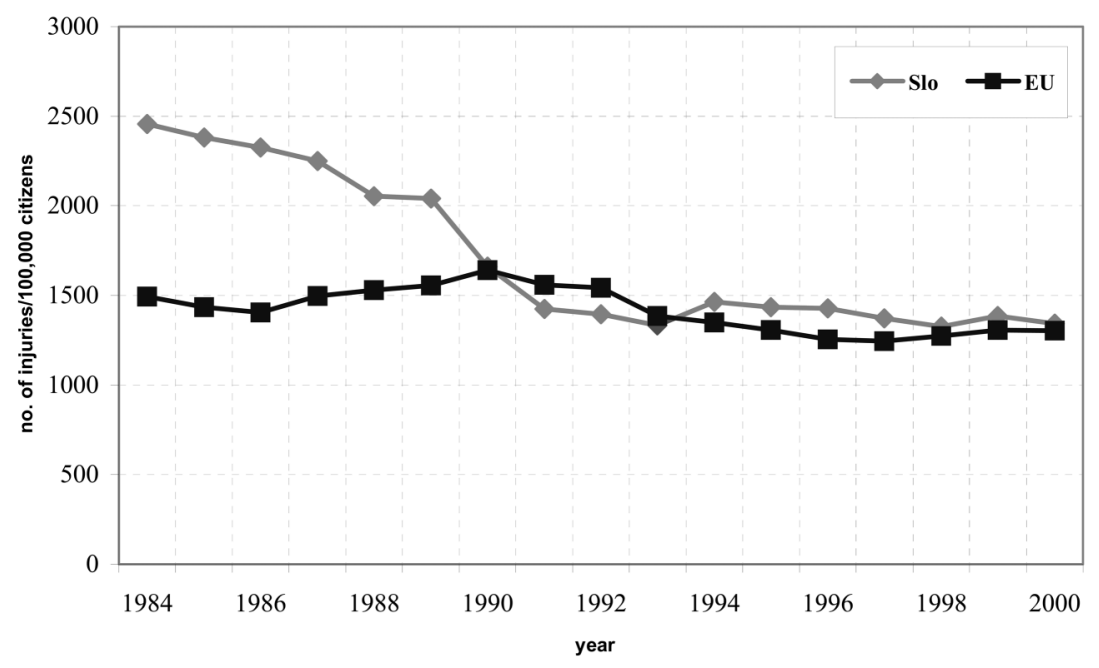

Fig. 2. Number of occupational injuries per 100,000 Slovene citizens compared to the EU average (1985-2000) $)^{4}$. 


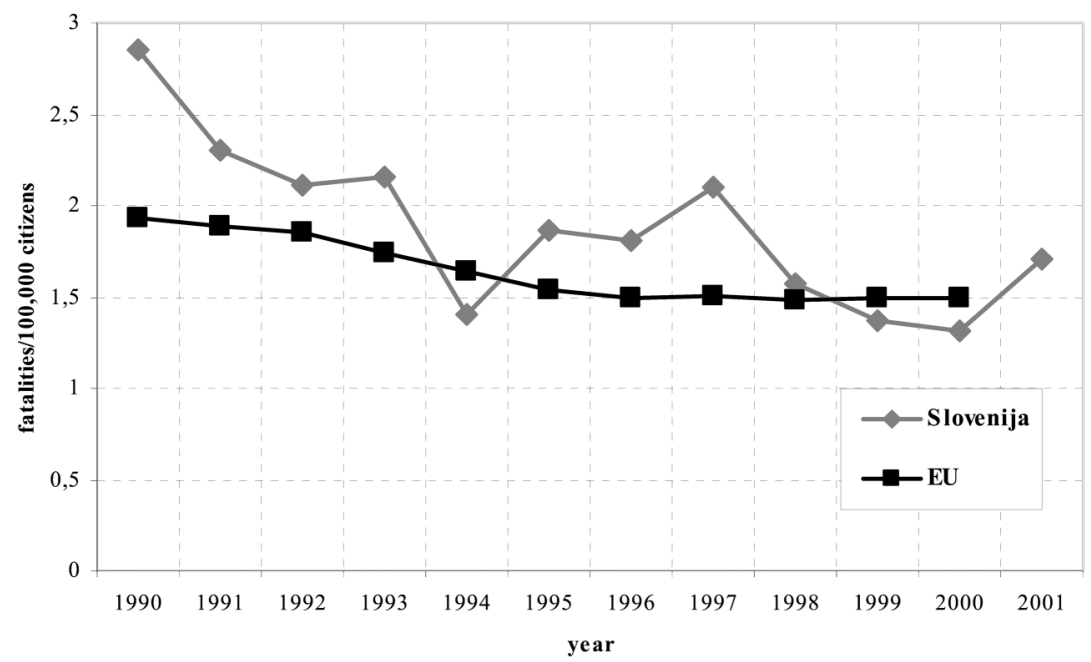

Fig. 3. Number of fatal occupational accidents per 100,000 Slovene citizens compared to the EU average (1990-2001) ${ }^{4}$.

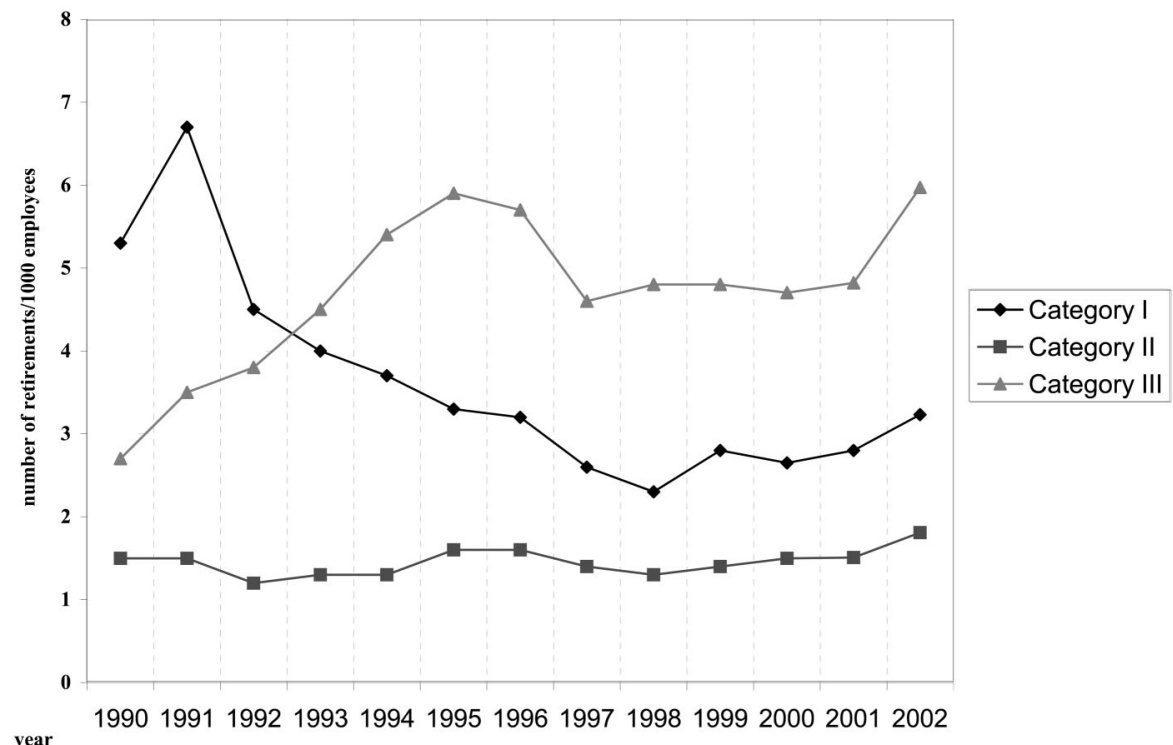

Fig. 4. Number of disability retirements per 1,000 employees (Slovenia, 1990-2002) ${ }^{4}$.

way to monitor occupational diseases in our country. On average 20-30 cases of occupational disablement are acknowledged every year. Thirty-one such cases were acknowledged in 2002: 17 workers suffered from occupational skin disease, 4 had asthma and 3 suffered from asbestosis, while ionizing radiation, vibrations and contagious diseases each claimed 2 workers. One worker was retired (category I, asbestosis), while 30 were acknowledged as category III invalids.

A new statute for a register of occupational diseases was passed by Parliament. It is substantially more extensive than the last one (only 46 occupational diseases). It now consists of 34 groups of hazardous chemicals, 5 kinds of hazardous physical factors and 3 kinds of hazardous biological factors; furthermore, occupational skin, respiratory and other diseases are now mentioned. Verification standards comparable to those of the EU are also being prepared, to finally bring consistency to this field.

\section{The Future of Occupational Medicine in Slovenia)}

As our way of life changes and the world becomes a global village, the needs and requirements of occupational medicine change with these changes. EU research has 
demonstrated that workloads have not decreased between 1995 and 2000. The consequences of noise, repetitive movements and inappropriate working postures still require medical attention. However, new challenges arise concerning:

* time pressure

* stress

* harmonizing work with personal lives of the employees.

Health problems will not disappear or diminish, only the nature of the problems will change. Simple causes, mechanisms and standpoints will be replaced by complex ones, which are harder to handle.

Other segments of society must become more constructively involved in occupational health and safety in order for the specialists of occupational medicine to function more efficiently. We have to become promoters of activities that would facilitate such involvement.

Values in our modern world change and so do values in medicine, especially occupational medicine, which has to follow economic and social development.

In this connection, we should follow the following recommendations made by the Union of European Specialists of Occupational Medicine:

1. All European workers should have the same access to the services of occupational medicine.

2. A special strategy needs to be created for workers of small and medium enterprises.

3. A special status should be given to occupational medicine inside the health care system. Other specialists should recognize the need to consult experts of occupational medicine in their own fields. Teams of experts should introduce economy to the knowledge the specialists of occupational medicine possess and teach how that knowledge can help employers to establish and implement preventive programs and measures and to fulfill the legal requirements of occupational health and safety.

4. Social and economic costs of illnesses and injuries are encouragement enough to extend the field of occupational medicine across Europe. Medical doctors at the primary level and family doctors should all be encouraged to take an interest in this field.

5. The main task of the Union of European Specialists is to ensure that there are enough medical doctors educated to satisfy the needs of the future of occupational medicine.

The knowledge and experience of specialists of occupational medicine are frequently applied in the area of environmental protection, especially when it comes to depositing toxic wastes.

Promoting health in the workplace is a vital task for specialists of occupational medicine. Protection from injuries, dangerous chemicals, dangerous work processes and other hazardous factors is the priority. However, the promotion of health should not exclude the eradication of bad habits, which can also influence the health of workers. Thus, workers and their representatives must cooperate closely with specialists of occupational medicine and their employers in deciding on appropriate programs of health promotion. The specialist of occupational medicine is becoming a fundamental member of the expert teams for health and safety at work. By advising on the nature of health protection, he is vitally contributing to the overall quality of company management.

We note that the time, when none actually saw the need for the field of occupational medicine, is long past. Entering the EU and implementing modern European legislation in occupational health and safety have already clearly indicated the direction of development. Naturally there will be obstacles on the way, but occupational medicine (together with occupational health care) in Slovenia is already making huge steps into becoming a modern "European" in terms of occupational medicine, with new tasks, functioning in the working environment, promoting health and humanity in the broadest senses of the words.

With the EU as its role-model, occupational medicine will have to move from offices into the working environment, where it will function in the field of primary prevention (treatment and improvement of the workplace) protecting the health, happiness and productivity of all employees.

\section{References}

1) Bilban M. Occupational medicine. Ljubljana: Institute of occupational safety, 1999: 18-45.

2) Dodič FM, Bilban M, Dšuban G. The system of occupational health and safety in Slovenia, Proceedings (CD). 16 World Congress on safety and Health at Work, Vienna 2002.

3) Bilban M, Teržan M. Development of occupational medicine in the area of Slovenia. International Journal of public health. Ljubljana: Institute of Public Health of the Republic of Slovenia, 2004 (in press).

4) Anon. Health Statistical Yearbook. Ljubljana: Institute of Public Health of the Republic of Slovenia, 2003.

5) Bilban M. Report of Extended Expert Collegium of Occupational, Traffic and Sport Medicine in Slovenia, Work and Health. Ljubljana: ZMDPS, 2003. 